\title{
Phosphonium nitrate ionic liquid catalysed electrophilic aromatic oxychlorination $\uparrow$
}

\author{
Marco Noè, ${ }^{a}$ Alvise Perosa, ${ }^{* a}$ Maurizio Selva ${ }^{a}$ and Luca Zambelli ${ }^{b}$ \\ Received 15th April 2010, Accepted 13th July 2010 \\ DOI: $10.1039 / \mathrm{cogc00004c}$
}

Trioctylmethylphosphonium nitrate $\left(\mathrm{P}_{8,8,8,1} \mathrm{NO}_{3}\right)$, an ionic liquid made via a green synthesis, catalyses electrophilic aromatic chlorination of arenes with $\mathrm{HCl}$ and air at $80^{\circ} \mathrm{C}$. The aromatic oxychlorination is truly catalytic in nitrate, proceeds without added solvents, and uses atmospheric oxygen as oxidant. The extent of chlorination can be controlled to yield selectively mono or dichlorinated products, and the ionic liquid catalyst can be recycled. Dependence of the chlorination rate on $\mathrm{HCl}$ and nitrate concentrations as well as on the rate of re-oxidation of the nitrogen intermediates by air, allowed us to propose a reaction mechanism.

\section{Introduction}

Chlorinated aromatic hydrocarbons are of substantial economic significance, and are important starting materials and additives in the production of high-quality insecticides, fungicides, herbicides, dyes, pharmaceuticals, disinfectants, rubbers, plastics, textiles, and electrical goods. ${ }^{1}$

Aromatic chlorination is usually achieved via electrophilic substitution. For example, the industrial syntheses of chlorobenzene and chlorotoluene are still largely based on the textbook liquid-phase chlorination process with gaseous chlorine in the presence of a Lewis acid catalyst ${ }^{2}\left(\right.$ e.g. $\mathrm{FeCl}_{3}$ ). This system however has an intrinsically low atom economy ${ }^{3}$ since only one of the two chlorine atoms is incorporated in the product, the other being wasted as chloride ( $\mathrm{HCl}$ or salt) which requires appropriate disposal. In addition the Lewis acid is often not catalytic, and the procedure requires chlorinated solvents. Since the methods involving chlorine gas are extremely well established from a process and economic standpoint, they are still widely preferred industrially despite the hazards and toxicity associated with their use. In this context therefore, any method which reduces the amount of chlorine upstream and downstream, and that improves on the environmental performance of the process is desirable.

Oxidative halogenation uses a more atom economical reagent for aromatic chlorination, i.e. the chloride $\left(\mathrm{Cl}^{-}\right)$moiety. In this case all the chlorine ends up in the product, the downfall being that chloride needs to be oxidized to an electrophilic " $\mathrm{Cl}^{+}$" species, hence the need for an additional oxidant such as aqua regia, ${ }^{4}$ hypochlorous acid, ${ }^{5}$ or hydrogen peroxide. ${ }^{6}$ In these cases, atom efficiency can still be maintained provided the oxidant can be used in catalytic amounts (and successively reoxidized for

aDipartimento di Scienze Ambientali, Università Ca' Foscari Venezia, Dorsoduro 2137, 30123, Venezia, Italy.E-mail: alvise@unive.it ${ }^{b}$ Galentis S.r.L., Via Delle Industrie 11, 30020, Marcon (Ve)

$\dagger$ Electronic supplementary information (ESI) available: Pictures of a representative experimental set up, anisole chlorination GC/MS data, anisole dichlorination GS/MS data, $p$-xylene dichlorination GC/MS data and isolated dichlo- $p$-xylenes NMR spectrum. See DOI: $10.1039 / \mathrm{c} 0 \mathrm{gc} 00004 \mathrm{c}$ example with air). A process of this kind was developed by Gulf for the oxychlorination of benzene in the liquid phase with aqueous hydrochloric acid, catalytic quantities of nitric acid, and air or oxygen. ${ }^{7}$

Thionyl chloride and $N$-chloro amides ${ }^{8}$ as electrophilic chlorinating stoichiometric reagents are here mentioned for completeness, but are usually lab-scale setups and intrinsically inefficient from an atom economy standpoint.

The reaction here described is the electrophilic aromatic chlorination using hydrochloric acid as chlorine source and nitrate as oxidant. The peculiarity lies in the use of a phosphonium nitrate ionic liquid as oxidant, along the lines of the papers by the groups of Earle ${ }^{9}$ and Chiappe, ${ }^{10}$ the only other earlier studies on this kind of systems. The driving force for the research here described was our recent collaboration with an industrial partner who asked to improve their aromatic chlorination process for the production of polymer intermediates. The two main problem areas of the process were tackled: (i) the use of large quantities of dichloromethane (DCM) as solvent, and (ii) the use of $\mathrm{Cl}_{2}$ as chlorinating agent. DCM is an effective but undesirable solvent, whose presence in consumer products is beginning to be regulated by the European Parliament ${ }^{11}$ since it is a suspected human carcinogen. $\mathrm{Cl}_{2}$ is dangerous and anti-atom economicas stated earlier-because half of the $\mathrm{Cl}$ atoms end up as waste. In the present case, compared to the findings previously reported, ${ }^{9,10}$ a deeper understanding of the factors affecting selectivity, kinetics, and the reaction mechanism are reported. This knowledge was then used to improve the overall rate and conversion performance of the nitrate-promoted monochlorination step, and to achieve multiple stepwise chlorination of model substrates.

\section{Results}

Following the previous accounts on the use of nitrate ionic liquids as catalysts, the electrophilic chlorination of anisole as the model substrate was investigated using four different ionic liquids as nitrate sources. Along with the recently reported trioctylmethylammonium $\left(\mathrm{N}_{8,8,8,1}\right)$ and -phosphonium 
$\left(\mathrm{P}_{8,8,8,1}\right),{ }^{12}$ butylisoquinolinium (BuisoQ) and butylmethylimidazolium (bmim) nitrate salts were also used (Fig. 1).

$$
\begin{aligned}
& \left(n-\mathrm{C}_{8} \mathrm{H}_{17}\right)_{3} \stackrel{\oplus}{\mathrm{NC}} \mathrm{H}_{3} \quad\left(n-\mathrm{C}_{8} \mathrm{H}_{17}\right)_{3} \stackrel{\oplus}{\mathrm{PCH}_{3}} \\
& \mathrm{~N}_{8,8,8,1} \quad \mathrm{P}_{8,8,8,1}
\end{aligned}
$$

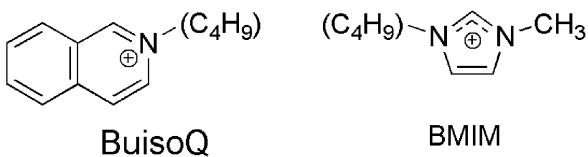

Fig. 1 Cations employed for the nitrate ionic liquids.

The $\mathrm{N}_{8,8,8,1} \mathrm{NO}_{3}$ and $\mathrm{P}_{8,8,8,1} \mathrm{NO}_{3}$ ionic liquids were prepared by a novel green synthetic procedure. ${ }^{12}$ This methodology involved reacting trioctylphosphine $\left(n-\mathrm{C}_{8} \mathrm{H}_{17}\right)_{3} \mathrm{P}$ with dimethylcarbonate (DMC: $\mathrm{CH}_{3} \mathrm{OCO}_{2} \mathrm{CH}_{3}$ ), and subsequently exchanging the methylcarbonate anion using nitric acid (Scheme 1 exemplifies the procedure for the phosphonium cation).

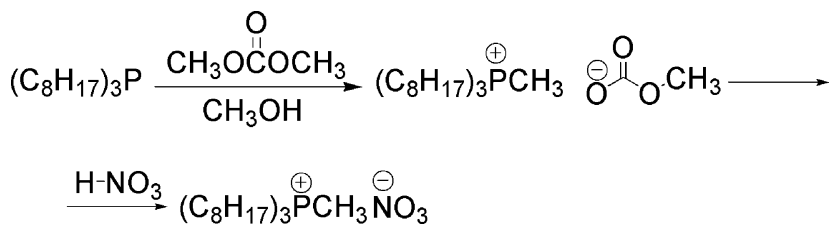

Scheme 1 Synthesis of $\mathrm{P}_{8,8,8,1} \mathrm{NO}_{3}$ from trioctylphosphine, dimethylcarbonate and nitric acid. ${ }^{12}$

All four nitrate ionic liquids promoted the chlorination of anisole with $>80 \%$ conversion at $80{ }^{\circ} \mathrm{C}$ using a molar ratio 2,2:1: 1 of $\mathrm{HCl}$ :anisole:IL respectively, in $23 \mathrm{~h}$ (Fig. 2). The reaction mixture was constituted by $\mathrm{HCl}_{\mathrm{aq}}$, anisole, and the IL, no other solvent being necessary.

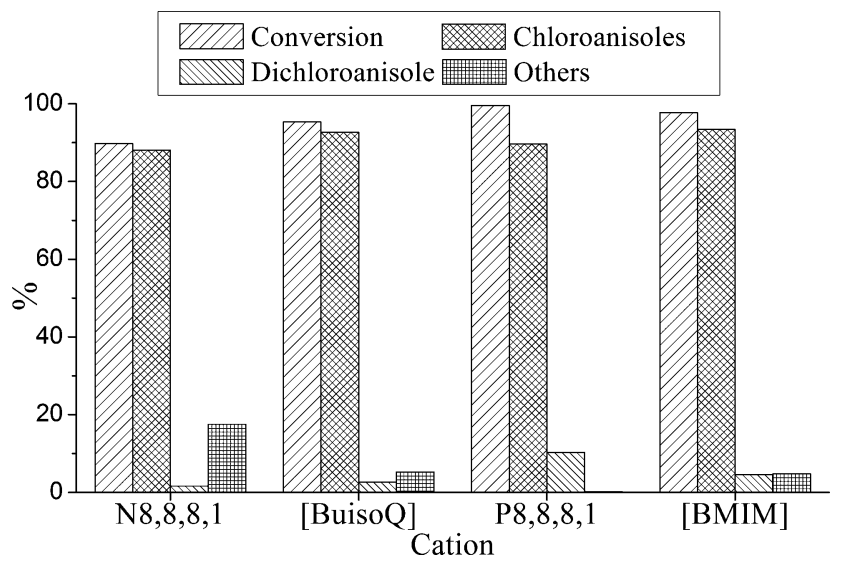

Fig. 2 Chlorinating efficiency of four nitrate ionic liquids.

Using $\mathrm{N}_{8,8,8,1} \mathrm{NO}_{3}$ as a nitrate source the conversion reached $90 \%$ with high selectivity $(99 \%)$, but significant amounts of chlorooctane, deriving from IL breakdown, were formed (17\%). BuisoQ and bmim nitrates behaved similarly to one another, and formed up to $5 \%$ of undesired products deriving from aromatic nitration. $\mathrm{P}_{8,8,8,1} \mathrm{NO}_{3}$ afforded the highest conversion $(>99 \%)$ and chlorination selectivity $(99 \%$ as sum of di- and monochloroanisoles), with the lowest amount of side-products, and was used thereafter.

In order to determine the optimal amount of nitrate ionic liquid, the electrophilic chlorination of $p$-xylene (less reactive than anisole) was conducted with varying substrate $/ \mathrm{P}_{8,8,8,1} \mathrm{NO}_{3}$ molar ratios of $0.5-1.0-2.0-4.0$, using 2.0 equivalents of $\mathrm{HCl}$ at $80{ }^{\circ} \mathrm{C}$ (Fig. 3).

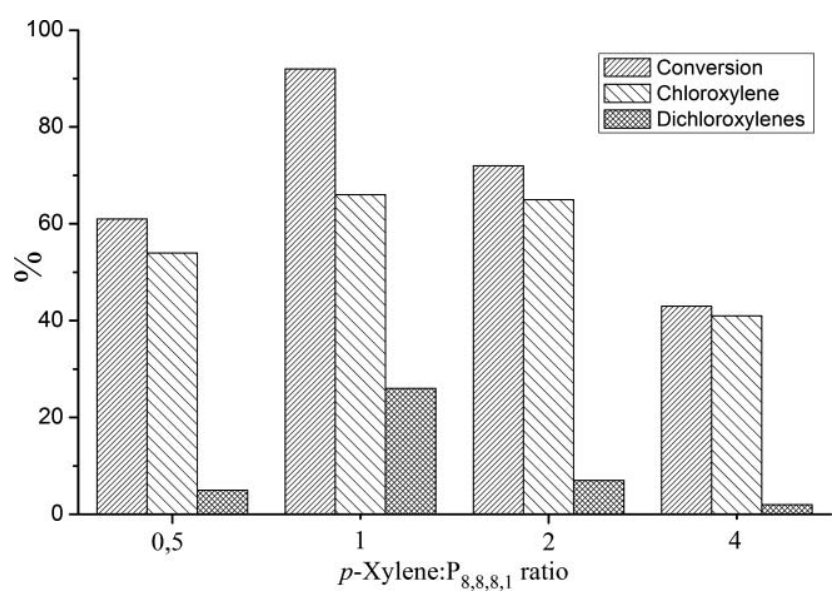

Fig. 3 Electrophilic chlorination of $p$-xylene with varying amounts of $\mathrm{P}_{8,8,8,1} \mathrm{NO}_{3}$.

After $24 \mathrm{~h}$ it was apparent that the optimal ratio was 1.0. Significantly, however, for xylene $/ \mathrm{P}_{8,8,8,1} \mathrm{NO}_{3}$ molar ratios of 2.0 and 4.0 , the reaction proceeded to $72 \%$ and $43 \%$ conversions respectively, indicative of catalysis by $\mathrm{P}_{8,8,8,1} \mathrm{NO}_{3}$. In fact, the total moles of chloride that were converted per mole of $\mathrm{P}_{8,8,8,1} \mathrm{NO}_{3}$ were greater than unity (1.8 and 2.0 respectively). Furthermore, dichloroxylenes were observed in all cases, up to $25 \%$ for the xylene $/ \mathrm{P}_{8,8,8,1} \mathrm{NO}_{3}$ molar ratio of $1: 1$.

A number of aromatic model substrates was subjected to the electrophilic chlorination conditions using $\mathrm{P}_{8,8,8,1} \mathrm{NO}_{3}$ : a mixture of aqueous $\mathrm{HCl}$, the aryl reagent, and $\mathrm{P}_{8,8,8,1} \mathrm{NO}_{3}$ was heated at $80{ }^{\circ} \mathrm{C}$ for the required time, and the products analysed by GC-MS. ${ }^{13}$

Table 1 shows the results of the chlorination of different aromatics with $\mathrm{HCl}$ using $\mathrm{P}_{8,8,8,1} \mathrm{NO}_{3}$ as promoter. The molar ratio of aromatic substrate to ionic liquid was initially set to 1 , based on the optimal amount of nitrate ionic liquid as determined above, as well as on the literature, ${ }^{9,10}$ although nitrate is in principle catalytic as seen before. The molar amount of substrate to HClaq was selected in the range between 1.0 and 2.4. One equivalent of $\mathrm{HCl}$ was sufficient for monochlorination of the activated substrates. In fact, anisole, xylene and toluene yielded the monochloro adducts respectively in $85 \%, 78 \%$, and $90 \%$ yields after 3 to 4 days at $80^{\circ} \mathrm{C}$ (entries 1, 5, 8 of Table 1). By doubling the molar amount of $\mathrm{HCl}$ the same activated substrates reached high conversions to the monochloro adduct significantly faster (3-24 h, entries 2, 6, 9 respectively). Under these conditions naphthalene was monochlorinated with good yields $(75 \%)$ in 4 days as well (entry 4$)$.

Deactivated aromatic substrates, such as chloro- and nitrobenzene yielded only traces of chlorinated products even in the presence of an excess of $\mathrm{HCl}$ (entries 11 and 12); while acetophenone and methoxyacetophenone underwent benzylic 
Table 1 Chlorination of arenes using a molar ratio substrate/ $\mathrm{P}_{8,8,8,1} \mathrm{NO}_{3}=1^{a}$

\begin{tabular}{|c|c|c|c|c|c|c|}
\hline$\#$ & Arene & $\begin{array}{l}\text { Molar ratio } \\
\text { Substrate/ } \\
\mathbf{P}_{8,8,8,1} \mathrm{NO}_{3}\end{array}$ & $\begin{array}{l}\mathrm{HCl} \mathrm{37 \%} \\
\text { (mol eq) }\end{array}$ & $\mathrm{t} / \mathrm{h}$ & $\mathrm{Cl}_{1}{ }^{b}(\%)$ & $\mathrm{Cl}_{2}^{c}(\%)$ \\
\hline 1 & \multirow[t]{2}{*}{ Anisole } & 1.0 & 1.0 & 60 & 85 & - \\
\hline 2 & & 1.0 & 2.2 & 3 & 97 & - \\
\hline 3 & \multirow[t]{2}{*}{ Naphthalene } & 1.0 & 1.0 & 48 & 29 & - \\
\hline 4 & & 1.0 & 2.4 & 90 & 75 & 3 \\
\hline 5 & \multirow[t]{3}{*}{ Xylene } & 1.0 & 1.2 & 96 & 78 & 1 \\
\hline 6 & & 1.0 & 2.4 & 24 & 62 & 26 \\
\hline 7 & & 2.0 & 1.2 & 96 & 75 & 1 \\
\hline 8 & \multirow[t]{3}{*}{ Toluene } & 1.0 & 1.2 & 96 & 90 & - \\
\hline 9 & & 1.0 & 2.4 & 20 & 85 & - \\
\hline 10 & & 2.1 & 1.1 & 96 & 94 & - \\
\hline 11 & Chlorobenzene & 1.0 & 4.3 & 24 & 7 & - \\
\hline 12 & Nitrobenzene & 1.0 & 2.4 & 26 & traces & - \\
\hline 13 & Acetophenone & 1.0 & 2.4 & 60 & $d$ & $d$ \\
\hline 14 & $\begin{array}{l}\text { 4-Methoxy } \\
\text { acetophenone }\end{array}$ & 1.0 & 2.4 & 60 & $d$ & $d$ \\
\hline $\begin{array}{l}{ }^{a} \mathrm{C} \\
{ }^{c} \mathrm{D} \\
\mathrm{Ar}-\end{array}$ & $\begin{array}{l}\text { nditions: } T= \\
\text { chlorinated prod } \\
\mathrm{COOH}, \mathrm{Ar}-\mathrm{CHO}\end{array}$ & $\begin{array}{l}{ }^{\circ} \mathrm{C} .{ }^{b} \mathrm{Mc} \\
\text { cts (by } \mathrm{G} \\
\text { ArCOCl. }\end{array}$ & $\begin{array}{l}\text { lochlorinat } \\
{ }^{d} \text { Benzyl }\end{array}$ & $\begin{array}{l}\text { ed } \\
\text { ic }\end{array}$ & $\begin{array}{l}\text { Oducts } \\
\text { idation }\end{array}$ & $\begin{array}{l}\text { by } \mathrm{GC} \text { ). } \\
\text { products: }\end{array}$ \\
\hline
\end{tabular}

Table 2 Catalyst recycling for anisole chlorination ${ }^{a}$

\begin{tabular}{ll}
\hline Recycle & Conversion $^{b}(\%)$ \\
\hline 1 & 95 \\
2 & 92 \\
3 & 93 \\
4 & 94
\end{tabular}

${ }^{a}$ Conditions: $T=80{ }^{\circ} \mathrm{C}$, molar ratio substrate $/ \mathrm{P}_{8,8,8,1} \mathrm{NO}_{3}=1$. ${ }^{b}$ Conversion (by GC).

oxidation (entries 13 and 14) and yielded mixtures of the corresponding carboxylic acids, aldehydes and acyl chlorides. To verify consistency on a larger scale ( $\sim 13$ times), a reaction was run on $2.0 \mathrm{~mL}$ of anisole with the corresponding molar quantities of $\mathrm{P}_{8,8,8,1} \mathrm{NO}_{3}$ and $\mathrm{HCl}$ under the conditions of entry 2. Reaction was complete in three hours $(90 \%$ chloroanisole by GC) and chloranisole was obtained as a pure product by vacuum distillation in $76 \%$ yield.

$\mathrm{P}_{8,8,8,1} \mathrm{NO}_{3}$ recycling was demonstrated using anisole as substrate under the conditions of entry 1 of Table 1 . Each recycle was conducted by extracting the organic products from the reaction mixture, removing residual water under vacuum, then adding fresh substrate and one equivalent of HClaq and heating at $80^{\circ} \mathrm{C}$ for an additional $120 \mathrm{~h}$ (Table 2). No decrease in activity was observed after four cycles.

By using two equivalents of $\mathrm{HCl}$, the dichlorination of the activated arenes (anisole, toluene and xylene) could also be accomplished. In this case, however, the presence of one additional equivalent of nitrate anion was required: this was added dropwise halfway through the reaction (i.e. after complete monochlorination) in the form of nitric acid (Table 3 ).

Dichloro-anisole, and mixtures of 2,5-dichloro- $p$-xylene and 2,3-dichloro- $p$-xylene were thus obtained after 60 and $72 \mathrm{~h}$ respectively (entries 1 and 2). Naphthalene yielded up to $50 \%$ dichloro-naphthalene after $90 \mathrm{~h}$ (entry 3); while toluene proved quite reluctant to dichlorination under these conditions (entry 4).
The dichlorination of anisole could also be carried out stepwise without the intermediate addition of nitric acid. The first step was performed in the presence of one equivalent of $\mathrm{HCl}$ : monochlorination of anisole occurred in 5 days, then the addition of a second equivalent of $\mathrm{HCl}$ yielded dichloroanisole $(92 \%)$ after 5 more days (Scheme 2).

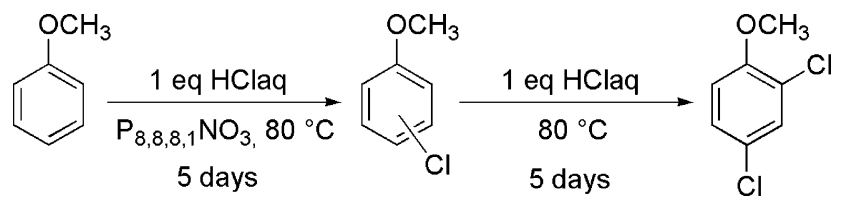

Scheme 2 The two-step dichlorination of anisole catalysed by $\mathrm{P}_{8,8,8,1} \mathrm{NO}_{3}$.

The second step was partially inhibited when oxygen was excluded from the reaction.

\section{Discussion}

The synthesis of the $\mathrm{P}_{8,8,8,1} \mathrm{NO}_{3}$ ionic liquid is inherently green for a number of reasons.

1 It uses dimethylcarbonate, a non-toxic and safe reagent ${ }^{14,15}$ instead of toxic quaternarising reagents such as dimethylsulfate and methyl halides. ${ }^{16}$

2 The ionic liquids that are obtained are intrinsically halide free, generally an advantage since residual halides are an undesirable impurity.

3 Operatively, the synthesis is simple, and workup-free, as the only co-products methanol and $\mathrm{CO}_{2}$ can be stripped simply by applying vacuum.

4 No waste is generated, thus eliminating the need for treatment, and the byproducts (methanol and carbon dioxide) can be easily removed and, in principle, recycled for the production of DMC.

5 No solvents, other than a small amount of methanol in the first step needed to homogenize the mixture, are used.

In addition, the liquids thus obtained are clear and colourless, as opposed to the ones made from dimethylsulfate and methyl halides that are often coloured.

Compared to other ILs, the $\mathrm{P}_{8,8,8,1} \mathrm{NO}_{3}$ ionic liquid proved to be the best in promoting the aromatic electrophilic chlorination reaction, in particular because the selectivity was higher than with all the other ionic liquids tested. In addition, with $\mathrm{P}_{8,8,8,1} \mathrm{NO}_{3}$ the reaction rate was significantly higher than that observed by Earle ${ }^{9}$ and Chiappe $^{10}$ using respectively $[\mathrm{bmim}] \mathrm{NO}_{3}$ and $[\mathrm{Hmim}] \mathrm{NO}_{3}$ as can be seen in Table 4. For example anisole chlorination was achieved in only $3 \mathrm{~h}$, using a $2.2 \mathrm{HCl}$ molar ratio (also on a preparative scale of $2 \mathrm{~g}$ ), with near quantitative conversion and selectivity in our case (entry 1), compared to $72 \mathrm{~h}(2.0 \mathrm{HCl}$ molar ratio $)$ or $48 \mathrm{~h}(1.0 \mathrm{HCl}$ molar ratio, but only $70 \%$ of product obtained) (entries 2 and 3). Furthermore the $\mathrm{P}_{8,8,8,1} \mathrm{NO}_{3}$ ionic liquid promoted a particularly good selectivity: for example in the case of $p$ xylene no alkyl chlorination or oxidation was observed (entry 4). Chiappe ${ }^{10}$ instead observed large amounts of $\alpha$-chloro- $p$-xylene (1-(chloromethyl)-4-methylbenzene) and the oxidation product 4-methyl-benzaldehyde (entry 5). 
Table 3 Dichlorination of arenes ${ }^{a}$

\begin{tabular}{|c|c|c|c|c|c|c|c|}
\hline$\#$ & Arene & $\mathrm{HCl} 37 \%$ (mol eq) & $\mathrm{Cl}_{1}^{b}(\%)$ & $\mathrm{t}_{1}{ }^{c} / \mathrm{h}$ & $\mathrm{HNO}_{3}{ }^{d}(\mathrm{~mol} \mathrm{eq})$ & $\mathrm{Cl}_{2}{ }^{e}(\%)$ & $\mathrm{t}_{2}^{f} / \mathrm{h}$ \\
\hline 1 & Anisole & 2.2 & 97 & 3 & 1.0 & 92 & 60 \\
\hline 2 & Xylene & 2.4 & 62 & 24 & 2.0 & $85^{g}$ & 72 \\
\hline 4 & Toluene & 2.4 & 85 & 20 & 2.0 & 10 & 72 \\
\hline
\end{tabular}

${ }^{a}$ Conditions: $T=80{ }^{\circ} \mathrm{C}$, molar ratio substrate $/ \mathrm{P}_{8,8,8,1} \mathrm{NO}_{3}=1 .{ }^{b}$ Monochlorinated products (by GC). ${ }^{c}$ Time for complete monochlorination. ${ }^{d} \mathrm{HNO}_{3}$ added once monochlorination was complete. ${ }^{e}$ Dichlorinated derivatives (by GC). ${ }^{f}$ Time for dichlorination. ${ }^{g}$ Isolated yield $=68 \%$.

Table 4 Chlorination of arenes: comparison between $\mathrm{P}_{8,8,8,1} \mathrm{NO}_{3},[\mathrm{bmim}] \mathrm{NO}_{3},{ }^{9}$ and $[\mathrm{Hmim}] \mathrm{NO}_{3}{ }^{10}$

\begin{tabular}{|c|c|c|c|c|c|c|c|c|}
\hline Run & Arene & Ionic liquid & Molar ratio substrate/IL & $\mathrm{HCl}$ (mol eq) & $T /{ }^{\circ} \mathrm{C}$ & $\mathrm{Cl}_{1}^{a}(\%)$ & Other $(\%)$ & $\operatorname{Time}^{b} / \mathrm{h}$ \\
\hline 1 & \multirow[t]{2}{*}{ Anisole } & $\mathrm{P}_{8,8,8,1} \mathrm{NO}_{3}$ & 1.0 & 2.2 & 80 & 97 & - & 3 \\
\hline 2 & & {$[\mathrm{bmim}] \mathrm{NO}_{3}$} & 1.25 & 2.0 & 100 & 99 & - & 72 \\
\hline 4 & \multirow[t]{2}{*}{ Xylene } & $\mathrm{P}_{8,8,8,1} \mathrm{NO}_{3}$ & 1.0 & 1.2 & 80 & 78 & - & 96 \\
\hline 5 & & {$[\mathrm{Hmim}] \mathrm{NO}_{3}$} & 2.0 & 1.0 & 80 & 33 & 17 & 48 \\
\hline 6 & \multirow[t]{2}{*}{ Naphthalene } & $\mathrm{P}_{8,8,8,1} \mathrm{NO}_{3}$ & 1.0 & 2.4 & 80 & 75 & - & 90 \\
\hline 7 & & {$[\mathrm{Hmim}] \mathrm{NO}_{3}$} & 2.0 & 1.0 & 80 & 24 & - & 48 \\
\hline
\end{tabular}

The comparison summarised in Table 4 indicated that the outcome of the chlorination reaction was strongly influenced by the structure of the cation of the ionic liquid.

A clear understanding of whether the electrophilic chlorination with $\mathrm{P}_{8,8,8,1} \mathrm{NO}_{3}$ and $\mathrm{HCl}$ was catalytic in nitrate was needed, in view of our aim to make this synthetic procedure useful on a preparative scale, and thus to address the issues on the chlorination process outlined in the beginning.

In previous accounts of similar reactions, slightly greater than equimolar amounts (1.25 eq ${ }^{9}$ at best), or up to 2 equivalents ${ }^{10}$ of nitrate ionic liquid as "catalyst" for the reaction were employed. Chiappe's work ${ }^{10}$ provided a first answer by demonstrating that by using 1.00 eq of $\mathrm{HCl}$ as chlorinating agent with respect to the aromatic, the ionic liquid was recovered unchanged and that it could be recycled repeatedly. It failed however to explain why two equivalents of $[\mathrm{Hmim}] \mathrm{NO}_{3}$ were needed, or to give evidence for the purported formation of chlorine gas as the chlorinating agent, and for nitrosyl chloride $(\mathrm{NOCl})$ as the first intermediate towards nitrate regeneration. In fact, the nitrate ionic liquid was defined by them as a "stoichiometric catalyst", or "promoter".

Our experiments confirmed that the phosphonium ionic liquid could be recycled, in fact anisole could be monochlorinated at least four times with the same $\mathrm{P}_{8,8,8,1} \mathrm{NO}_{3}$. It was however significant that recycling the system was possible only by using a stoichiometric amount of $\mathrm{HCl}$ and very long reaction times $(120 \mathrm{~h})$. As noted before, with no excess of acid the reaction became longer even with a very active aromatic substrate like anisole (Scheme 2). Attempts to accelerate the reaction by operating with a large excess of $\mathrm{HCl}$ killed the catalyst. The spent $\mathrm{P}_{8,8,8,1} \mathrm{Cl}$ catalyst was characterised by chloride titration. At the end of each cycle the catalyst could be regenerated by adding concentrated aqueous nitric acid, thus exchanging the chloride anion with nitrate. Similarly, Earle's work ${ }^{9}$ reported electrophilic chlorination using bmim chloride together with nitric acid, indicating that a metathetic anion exchange took place in situ.

In summary, when an excess of hydrochloric acid was used the nitrate ionic liquid worked as a stoichiometric reagent and fast reactions occurred. At the other extreme, when $\mathrm{HCl}$ was used in equimolar amounts, the reaction was very slow, and the rate determining re-oxidation of the reduced nitrogen species by air permitted high conversion and catalyst reutilization. This was demonstrated by recycling experiments and by chlorinating both $p$-xylene and toluene using a $2: 1$ substrate:IL ratio. Under these conditions close to quantitative conversion was observed with very high selectivity (Table 1, entries 7 and 10), implying that the nitrate ionic liquid is in fact a catalyst.

The above evidence prompted us to reconsider the mechanism previously reported, and to propose a new hypothesis to account for the nitrate catalysed electrophilic aromatic chlorination (Scheme 3), that does not require formation of $\mathrm{Cl}_{2}$ or $\mathrm{NOCl}$. It involves oxidation of chloride by nitrate to yield nitrous acid $\left(\mathrm{HNO}_{2}\right)$ and hypochlorous acid $(\mathrm{HOCl})$, the active chlorinating species (step 1), based on literature reports. ${ }^{17}$ Regeneration of nitric acid can then occur by disproportionation of nitrous acid $\left(\mathrm{HNO}_{2}\right)$ to nitric acid $\left(\mathrm{HNO}_{3}\right)$ and nitric oxide (NO) (step 2). Nitric oxide is then oxidised instantaneously by air to observable brown nitrogen dioxide $\left(\mathrm{NO}_{2}\right)$ (step 3), which in turn reacts with water to give nitric $\left(\mathrm{HNO}_{3}\right)$ and nitrous $\left(\mathrm{HNO}_{2}\right)$ acids (step 4). The latter disproportionates again to nitric acid and nitric oxide (step 5). The molar sum of all these redox and disproportionation reactions involving nitrogenoxygen species shows that only one mole of nitrate is consumed and continuously regenerated for each mole of reactant and of chloride. No benefits were observed by carrying out the reaction under pure oxygen.

The global reaction (eqn (1)) is therefore catalytic in nitrate, and uses oxygen as oxidant. 


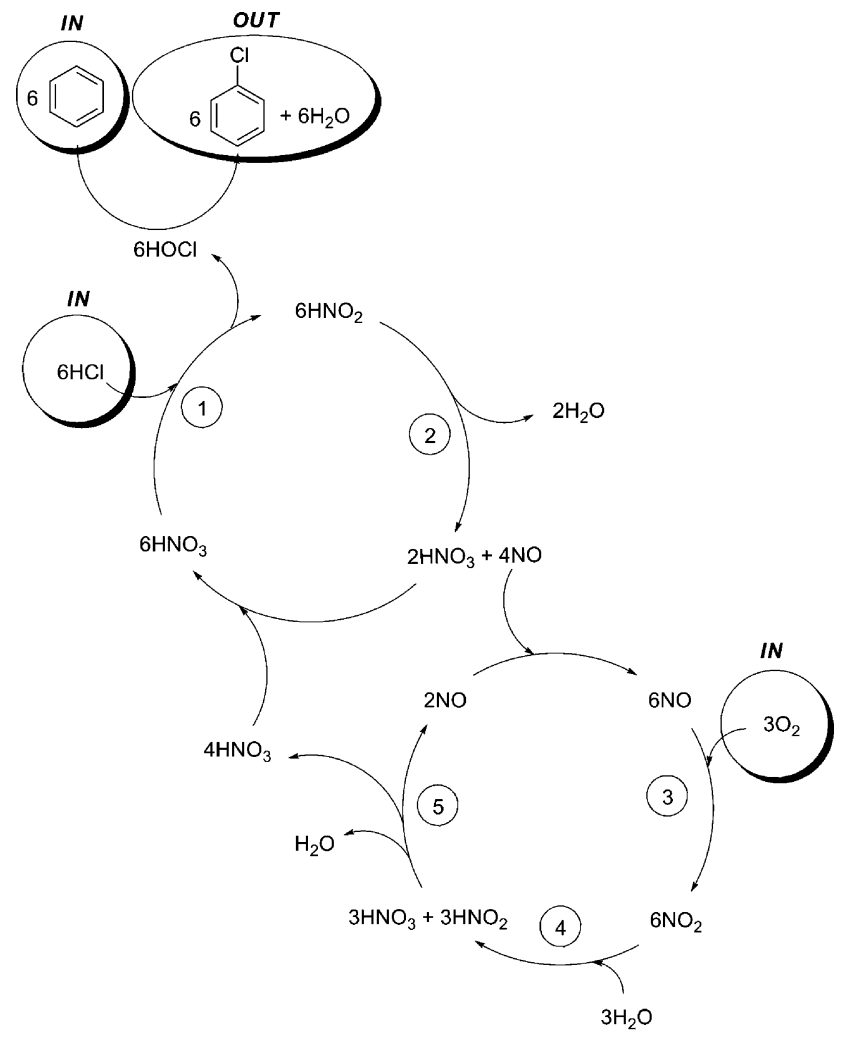

Scheme 3 Proposed mechanism for nitrate catalysed electrophilic chlorination with $\mathrm{HCl}$.

$$
6 \mathrm{Ar}-\mathrm{H}+6 \mathrm{HCl}+3 \mathrm{O}_{2} \rightarrow 6 \mathrm{Ar}-\mathrm{Cl}+6 \mathrm{H}_{2} \mathrm{O}
$$

Dichlorination was more difficult, in fact addition of an excess of hydrochloric acid from the beginning did not yield quantitative amounts of dichlorinated products and further addition of $\mathrm{HCl}$ did not drive the reaction to completion but rather caused the catalyst to become inactive. The trick to achieve dichlorination was to add one equivalent of nitric acid half-way through the reaction (Table 3) to regenerate the $\mathrm{P}_{8,8,8,1} \mathrm{NO}_{3}$ catalyst.

Further evidence for the proposed catalytic mechanism, where the rate determining step is reoxidation to nitrate, was obtained by running the dichlorination in two steps (Scheme 2). In this case, only one equivalent of $\mathrm{P}_{8,8,8,1} \mathrm{NO}_{3}$ was used and no further addition of nitric acid was necessary, on condition that a long period was allowed for spontaneous regeneration of $\mathrm{NO}_{3}{ }^{-}$. In addition, exclusion of air from the reaction of Scheme 2 inhibited the second step, indicating that regeneration of the catalyst requires oxygen. In this example the atom economy was optimal as $100 \%$ of chlorine was incorporated in the product and the nitrate ionic liquid was effectively catalytic.

\section{Conclusions}

The work here described improves the understanding of the electophilic aromatic chlorination process with $\mathrm{HCl}$, of its mechanism and of the factors that control rates, yields and selectivity. Catalysis by nitrate ionic liquids is established, as well as the fact that the kinetic bottleneck is represented by regeneration of the nitrate oxidant with atmospheric oxygen. Methods to overcome this drawback are indicated. By using $\mathrm{P}_{8,8,8,1} \mathrm{NO}_{3}$, chloroanisoles were obtained more than twenty times faster compared to the previously reported procedure involving the use of $[\mathrm{bmim}] \mathrm{NO}_{3},{ }^{9}$ and at a lower reaction temperature $\left(80{ }^{\circ} \mathrm{C}\right.$ instead of $\left.100{ }^{\circ} \mathrm{C}\right)$. Furthermore, quantitative (i.e. $100 \%$ selectivity) ring chlorination could be obtained for $p$ xylene with $\mathrm{P}_{8,8,8,1} \mathrm{NO}_{3}$, in contrast with $66 \%$ selectivity (due to concurrent benzylic chlorination and oxidation) in the case of $[\mathrm{Hmim}] \mathrm{NO}_{3} .{ }^{10}$ The knowledge collected here provides deeper comprehension of points that have emerged previously in the literature, and poses the basis for implementation of this synthetic methodology. In addition, the reported electrophilic aromatic chlorination reaction uses HClaq as chlorine source and is catalysed by $\mathrm{P}_{8,8,8,1} \mathrm{NO}_{3}$ in the absence of organic solvents, making it a greener alternative to processes which involve $\mathrm{Cl}_{2}$ and organic (usually chlorinated) solvents: the products can be isolated by distillation, no solvent is required for purification, and $100 \%$ of chlorine is utilised. The reactive electrophilic species is an oxidized form of chlorine " $\mathrm{Cl}^{+}$" - presumably $\mathrm{HOCl}$ - that is generated by the oxidation of chloride by nitrate, which in turn is regenerated by oxidation with air. With respect to traditional procedures, the present methodology improves on at least 6 of the 12 principles of green chemistry: better atom economy, use of catalysis, use of an alternative solvent ${ }^{18} /$ catalyst (made by a green synthesis), reduced waste, use of safer reagents, safer synthetic procedures, lower potential for accidents. It represents an improvement from implementing one or two of the principles (greenish chemistry), to abiding by as many of the principles as possible (greener chemistry).

\section{Experimental section}

\section{General}

Reagents were ACS grade and used as received.

GC-MS analyses were performed with a HP-5890 gaschromatograph equipped with a HP-5MS capillary column (30 $\mathrm{m} \times 0.25 \mathrm{~mm}$; coating thickness $0.25 \mu \mathrm{m}$ ) and a HP-5970 quadrupole mass detector (EI, $70 \mathrm{eV}$ ).

Analytical conditions: injector and transfer line temperatures 260 and $280{ }^{\circ} \mathrm{C}$ respectively; oven temperature programmed from $50{ }^{\circ} \mathrm{C}$ (isothermal condition for three minutes) to $250{ }^{\circ} \mathrm{C}$ at $10{ }^{\circ} \mathrm{C} \mathrm{min}{ }^{-1}$; carrier gas helium at $1 \mathrm{ml} \mathrm{min}^{-1}$; split ratio $1: 20$. The ${ }^{1} \mathrm{H}$ NMR spectra were obtained in $\mathrm{CDCl}_{3}$ with a $400 \mathrm{MHz}$ instrument using TMS as the internal reference.

\section{Ionic liquids}

Phosphonium and ammonium ionic liquids were prepared according to a new method recently reported by us. ${ }^{12}$ As reported in Scheme 1, trioctylamine and trioctylphosphine were set to react with dimethylcarbonate to obtain methyltrioctylammonium and methyltrioctylphosphonium methylcarbonate salts respectively. These compounds were anion-exchanged by reaction with nitric acid (Scheme 1) to yield the corresponding nitrate salts $\mathrm{N}_{8,8,8,1} \mathrm{NO}_{3}$ and $\mathrm{P}_{8,8,8,1} \mathrm{NO}_{3}$.

$N$-Butyl isoquinolinium bromide was prepared by $N$ alkylation of isoquinoline with butyl bromide. $N$-Alkylisoquinolinium nitrate $\left(\right.$ BuisoQNO${ }_{3}$ ) was prepared by metathesis in methanol solution from the respective bromide salts with an equimolar amount of $\mathrm{AgNO}_{3}$. 
1-n-Butyl-3-methylimidazolium chloride (bmimCl) was prepared by $N$-alkylation of methylimidazole with butyl chloride. 1$n$-Butyl-3-methylimidazolium nitrate $\left(\mathrm{bmimNO}_{3}\right)$ was prepared by metathesis in methanol solution from the respective chloride salts with an equimolar amount of $\mathrm{AgNO}_{3}$.

\section{Chlorination reactions}

Note. All the reactions were carried in a flask equipped with a reflux condenser open to the air. At the end of reactions the mixtures, after cooling at room temperature, were extracted with hexane $(4 \times 2 \mathrm{~mL})$. The $\%$ composition of the combined extracts was determined by GC-MS. For a representative product (dichloroxylenes, entry 2, Table 3 ), the yield was confirmed by isolating and purifying the product via FCC. All structures were assigned by comparison to authentic samples via GC-MS and ${ }^{1} \mathrm{H} \mathrm{NMR}$.

Chloroanisoles. Aqueous $\mathrm{HCl}(37 \%, 3.14 \mathrm{mmol}, 0.26 \mathrm{~mL})$ was added to anisole $(1.4 \mathrm{mmol}, 0.15 \mathrm{~mL})$ and $\mathrm{P}_{8,8,8,1} \mathrm{NO}_{3}$ $(1.4 \mathrm{mmol}, 630 \mathrm{mg})$. The resulting mixture was heated at $80{ }^{\circ} \mathrm{C}$ for $3 \mathrm{~h}$ (97\%: $75 \%$ para and 22\% ortho isomers).

Dichloroanisole (Method A). To the previously described reaction mixture, after $3 \mathrm{~h}$ at $80{ }^{\circ} \mathrm{C}$ was added aqueous $\mathrm{HNO}_{3}(69 \%, 1.4 \mathrm{mmol}, 0.09 \mathrm{ml})$ and the reaction mixture was maintained at the same temperature for $60 \mathrm{~h}(92 \%$ : $90 \%$ orthopara, $2 \%$ ortho-ortho isomers and $3 \%$ trichloro anisole).

Dichloroanisole (Method B). Aqueous $\mathrm{HCl}(37 \%, 1.4 \mathrm{mmol}$, $0.12 \mathrm{~mL})$ was added to anisole $(1.4 \mathrm{mmol}, 0.15 \mathrm{~mL})$ and of $\mathrm{P}_{8,8,8,1} \mathrm{NO}_{3}$ (1.4 mmol, $\left.630 \mathrm{mg}\right)$. The resulting mixture was heated at $80{ }^{\circ} \mathrm{C}$ for 5 days. Then additional aqueous $\mathrm{HCl}(37 \%$, $1.4 \mathrm{mmol}, 0.12 \mathrm{~mL}$ ) was added. The mixture was allowed to react at the same temperature for 5 more days (92\%: 91\% ortho-para and $1 \%$ ortho-ortho isomers).

Chloroanisoles (larger scale). Aqueous $\mathrm{HCl}$ (37\%, $40.5 \mathrm{mmol}, 3.35 \mathrm{~mL}$ ) was added to anisole $(18.39 \mathrm{mmol}$, $2.00 \mathrm{~mL})$ and $\mathrm{P}_{8,8,8,1} \mathrm{NO}_{3}(18.39 \mathrm{mmol}, 8.24 \mathrm{~g})$. The resulting mixture was heated at $80{ }^{\circ} \mathrm{C}$ for $3 \mathrm{~h}$. $(90 \%: 2: 1$ para - ortho ratio). The products were recovered and vacuum distilled to yield $2.003 \mathrm{~g}$ of chloroanisoles $(76 \%)$.

Chloro-p-xylene. Aqueous $\mathrm{HCl}(37 \%, 1.7 \mathrm{mmol}, 0.15 \mathrm{~mL})$ was added to 1,4-dimethylbenzene (1.4 mmol, $0.17 \mathrm{~mL})$ and $\mathrm{P}_{8,8,8,1} \mathrm{NO}_{3}(1.4 \mathrm{mmol}, 630 \mathrm{mg})$. The resulting mixture was heated at $80{ }^{\circ} \mathrm{C}$ for $96 \mathrm{~h}(78 \%)$.

Dichloro-p-xylenes. Aqueous $\mathrm{HCl}(37 \%, 3.4 \mathrm{mmol}$, $0.28 \mathrm{~mL}$ ) was added to 1,4-dimethylbenzene (1.4 mmol, $0.17 \mathrm{~mL})$ and $\mathrm{P}_{8,8,8,1} \mathrm{NO}_{3}(1.4 \mathrm{mmol}, 630 \mathrm{mg})$. The resulting mixture was heated at $80{ }^{\circ} \mathrm{C}$. After $24 \mathrm{~h}$ aqueous $\mathrm{HNO}_{3}(69 \%$, $1.4 \mathrm{mmol}, 0.09 \mathrm{ml}$ ) was added and the resulting mixture stirred for $48 \mathrm{~h}$. Then one additional equivalent of nitric acid was introduced and the reaction was carried out for an additional $48 \mathrm{~h}(85 \%$ : $60 \% 2,5$ and $40 \% 2,3$ isomers).

Chlorotoluene. Aqueous $\mathrm{HCl}(37 \%, 1.7 \mathrm{mmol}, 0.15 \mathrm{~mL})$ was added to toluene (1.4 mmol, $0.15 \mathrm{~mL}$ ) and $\mathrm{P}_{8,8,8,1} \mathrm{NO}_{3}(1.4 \mathrm{mmol}$, $630 \mathrm{mg}$ ). The resulting mixture was heated at $80{ }^{\circ} \mathrm{C}$ for $96 \mathrm{~h}$ (90\%: 47\% para and $43 \%$ ortho isomers).
Dichlorotoluene. Aqueous $\mathrm{HCl}(37 \%, 3.4 \mathrm{mmol}, 0.28 \mathrm{~mL})$ was added to toluene $(1.4 \mathrm{mmol}, 0.15 \mathrm{~mL})$ and $\mathrm{P}_{8,8,8,1} \mathrm{NO}_{3}$ $(1.4 \mathrm{mmol}, 630 \mathrm{mg})$. The resulting mixture was heated at $80{ }^{\circ} \mathrm{C}$. After $24 \mathrm{~h} \mathrm{HNO}_{3}(69 \%, 1.4 \mathrm{mmol}, 0.09 \mathrm{~mL})$ was added and the mixture was stirred for an additional $72 \mathrm{~h}(10 \%)$.

1-Chloronaphthalene. Aqueous $\mathrm{HCl}(37 \%, 3.4 \mathrm{mmol}$, $0.28 \mathrm{~mL})$ was added to naphthalene $(1.5 \mathrm{mmol}, 192 \mathrm{mg})$ and $\mathrm{P}_{8,8,8,1} \mathrm{NO}_{3}(1.5 \mathrm{mmol}, 670 \mathrm{mg})$. The resulting mixture was heated at $80{ }^{\circ} \mathrm{C}$ for $90 \mathrm{~h}(78 \%)$.

Dichloronaphthalene. To the previously described reaction mixture, after $90 \mathrm{~h}$ at $80{ }^{\circ} \mathrm{C}$, aqueous $\mathrm{HNO}_{3}(69 \%, 1.5 \mathrm{mmol}$, $0.10 \mathrm{ml}$ ) was added, and the reaction mixture was maintained at the same temperature for an additional $90 \mathrm{~h} \mathrm{(53 \% ).}$

Recycling procedure. In the first cycle, aqueous $\mathrm{HCl}(37 \%$, $1.4 \mathrm{mmol}, 0.12 \mathrm{~mL})$ was added to anisole $(1.4 \mathrm{mmol}, 0.15 \mathrm{~mL})$ and $\mathrm{P}_{8,8,8,1} \mathrm{NO}_{3}(1.4 \mathrm{mmol}, 630 \mathrm{mg})$. The resulting mixture was heated at $80{ }^{\circ} \mathrm{C}$ for $120 \mathrm{~h}$. After product extraction, traces of organic solvents and water were eliminated under reduced pressure. A fresh amount of substrate and $\mathrm{HCl}(1.4 \mathrm{mmol}$, $0.12 \mathrm{~mL}$ and $1.4 \mathrm{mmol}, 0.15 \mathrm{~mL}$, respectively) were then added to the residual mixture which was then heated again for the next cycle.

Chloride assay. A $50 \mu \mathrm{M}$ aqueous solution of $\mathrm{AgNO}_{3}$ was used to titrate a sample of spent ionic liquid (around $200 \mathrm{mg}$ ) dissolved in methanol $(100 \mathrm{~mL}) .1 \mathrm{~mL}$ of a solution of $\mathrm{K}_{2} \mathrm{Cr}_{2} \mathrm{O}_{7}$ $(10 \% \mathrm{w} / \mathrm{v})$ was used for each sample as indicator.

\section{Acknowledgements}

The authors wish to thank Ministero dell'Istruzione Università e Ricerca, and Regione Veneto for funding.

\section{References}

1 M. Rossberg, W. Lendle, G. Pfleiderer, A. Tögel, E.-L. Dreher, E. Langer, H. Rassaerts, P. Kleinschmidt, H. Strack, R. Cook, U. Beck, K.-A. Lipper, T. R. Torkelson, E. Löser, K. K. Beutel and T. Mann, Chlorinated Hydrocarbons in Ullmann's Encylopedia of Industrial Chemistry, 7th edn, Wiley VCH, Weinheim, 2006 , 10.1002/14356007.a06_233.pub2.

2 P. Kovacic and N. O. Brac, J. Am,. Chem. Soc., 1954, 76, 54915494.

3 Atom economy is defined as: $\mathrm{AE}=\left[\mathrm{MW}\left(\mathrm{g} \mathrm{mol}^{-1}\right)\right.$ product $] /\left[\sum \mathrm{MW}(\mathrm{g}\right.$ $\mathrm{mol}^{-1}$ )of all reagents] $\times 100$; see also B. M. Trost, Science, 1991, 254, 1471-1477.

4 R. L. Datta and F. V. Fernandes, J. Am,. Chem. Soc., 1916, 38, 1809 1813.

5 S. O. Nwaukwa and P. M. Keehn, Synth. Comm., 1989, 19, 799 804

6 R. Ben-Daniel, S. P. de Visser, S. Shaik and R. Neumann, J. Am, Chem. Soc., 2003, 125, 12116-12117.

7 US Pat. 3636170, 1972.

8 S. Kajigaeshi, M Moriwaki, T. Tanaka, S. Fujisaki, T. Kakinami and T. Okamoto, Chem. Soc. Perkin Trans. 1, 1990, 897-899.

9 M. J. Earle, S. P. Katdare and K. R. Seddon, Org. Lett., 2004, 6, 707-710.

10 C. Chiappe, E. Leandri and M. Tebano, Green Chem., 2006, 8, 742 745 .

11 Decision No. 455/2009/EC of the European Parliament and of the Council, 6 May 2009.

12 M. Fabris, V. Lucchini, M. Noè, A. Perosa and M. Selva, Chem. Eur. J., 2009, 15, 12273-12282. 
13 GC yields of Tables 1, 3, and 4 do not add up to 100: the difference is unreacted starting material unless otherwise stated.

14 M. Selva, P. Tundo and A. Perosa, J. Org,. Chem., 2001, 66, 677-680; M. Selva, P. Tundo and A. Perosa, J. Org. Chem., 2002, 67, 92389247; M. Selva, P. Tundo and A. Perosa, J. Org. Chem., 2003, 68, 7374-7378.

15 M. Selva and A. Perosa, Green Chem., 2008, 10, 457-464.
16 J. D. Holbrey, W. M. Reichert, R. P. Swatloski, G. A. Broker, W. R. Pitner, K. R. Seddon and R. D. Rogers, Green Chem., 2002, 4, 407413.

17 C. G. Swain and D. R. Crist, J. Am.. Chem. Soc., 1972, 94, 3195 3200.

18 See for example: J. Pavlinac, M. Zupan, K. K. Laali and S. Stavber, Tetrahedron, 2009, 65, 5625-5662. 